\title{
Impact of Fuel Exposure on Ventilatory Function among Petrol Pump Attendants in Thies, Senegal
}

\author{
Arame Mbengue ${ }^{1}$, Mame Saloum Coly², Salimata Houndjo Faye ${ }^{4}$, Abdou Khadir Sow ${ }^{3}$ \\ Mor Diaw ${ }^{3}$, Fatou Bintou Sarr ${ }^{1}$ \\ ${ }^{1}$ Professor, ${ }^{2}$ Assistant Professor, Laboratory of Physiology, UFR of Health Sciences of Thies, Service Functional \\ Explorations of the Regional Hospital of Thies, Senegal, ${ }^{3}$ Senior Assistant Professor, ${ }^{4}$ Assistant Professor, \\ Laboratory Physiology and Functional Explorations, FMPO/UCAD, Dakar, Senegal
}

\begin{abstract}
Introduction: Petrol pump attendants are exposed to toxic substances in fuels. The release of petrol fumes during fuel refuelling is a repeated and often harmful source of exposure for petrol pump attendants. The purpose of our study was to evaluate the ventilatory disorders related to fuel exposure among petrol pump attendants.
\end{abstract}

Materials and Method: Forty petrol pump attendants have been recruited. The study included a medical survey with a questionnaire that examined anthropometric characteristics, seniority, smoking habits and working conditions. The study included a medical survey with a questionnaire that examined anthropometric characteristics, seniority, smoking habits and working conditions. All our subjects received a basic and post-bronchodilator spirometry. The targeted respiratory functional disorders were bronchial obstruction, restrictive syndrome and mixed syndrome. Obstructive syndrome has been reported on the basis of: FEV1/ FVC and/or FEF $25-75 \%$ less than 80\%. Functional restriction was defined on the basis of a decrease in FVC $<80 \%$ and the normal FEV1/FVC ratio. The mixed syndrome was retained firstly before the combination of the two obstructive and restrictive spirometric anomalies.

Results: We noted $20 \%$ of active smokers and $25 \%$ of ex-smokers. The average length of service was $9.4 \pm 7.05$ years. All of the petrol pump attendants used incomplete means of protection. No employee was receiving medical follow-up. Most subjects (52.5\%) were unaware of the risks associated with fuel exposure. Respiratory functional disorders were dominated by isolated obstructive ventilatory disorder (OVD) in $45 \%$ of subjects and were mainly located in the distal bronchi $(65 \%)$. Besides, $12.5 \%$ of subjects had an isolated restrictive functional disorder (RFD) and a mixed syndrome in $27.5 \%$ of cases. Obstructive and mixed ventilatory disorders were more important according to smoking status. The different ventilatory disorders (VD) appeared from the beginning of exposure with a predominance of obstructive ventilatory disorders. Mixed ventilatory disorders increased significantly after 10 years of exposure.

Conclusion: Exposure to petrol / diesel fumes has harmful effects on the ventilatory function of petrol pump attendants.

Key words: petrol pump attendant, fuel, ventilatory disorders, spirometry, Senegal.

\section{Introduction}

\section{Corresponding Author:}

Arame Mbengue,

Department of Biology, UFR of Health Sciences, University of THIES, SENEGAL, email: aramembengue08@live.fr
Personnel working in petrol stations are exposed not only to air pollutants, but also to organic and inorganic components in fuels (diesel oil and petrol). During the distribution chain of these fuels, hydrocarbon fumes are released, leading to overexposure of employees working 
in petrol stations, particularly petrol pump attendants. The fuels contain a variety of chemicals including small amounts of benzene and sometimes lead that are absorbed by the human body through the respiratory tract or through skin contact. These can cause respiratory symptoms and impaired ventilatory functions ${ }^{1}$. Animals exposed to diesel exhaust gas have been shown to develop impaired lung function ${ }^{2,3}$. In Senegal, a developing country, the fuel trade is growing considerably with the advent of new local fuel distribution companies. Every day, about fifty employees working in the 26 petrol stations in the city of Thiès are directly exposed to the fuels and the additives they contain. The purpose of this study was to determine the ventilatory disorders related to fuel exposure among petrol pump attendants working in the city of Thiès (Senegal).

\section{Material and Method}

\section{Participants}

The study protocol was approved by the ethics committee of the University of Thiès. We conducted a descriptive and analytical cross-sectional study over a three-month period (29 June to 02 October, 2018). Our study population consisted of fuel-exposed petrol pump attendants, all male. All these workers had at least one year of seniority. The study included a medical survey (questionnaire, clinical examination and spirometry). The questionnaire covered physical characteristics (gender, height, weight, age), seniority in the activity, working conditions, smoking habits. For cigarette smoking intoxication, we have identified active smokers, ex-smokers and non-smokers. Subjects are categorized as smokers: those who smoked during the 30 days preceding the survey, former smokers: those who smoked for more than 30 days but did not smoke during the 30 days preceding the survey; non-smokers are those who had never smoked or who had smoked for less than 30 days. The exclusion criteria were the presence of a thoracic deformity or a progressive cardiopulmonary pathology known at the time of the study.

Spirometric parameters: Basic and postbronchodilator spirometry were performed in all our subjects. Spirometry was performed using a regularly calibrated Jaeger PNEUMO Care Fusion device coupled with a computer in which data analysis software is installed. Explanations and supporting illustrations were provided in advance regarding the conduct of the examination for better cooperation of the subjects. After the various tests were performed, lung volumes and bronchial flows were examined and the rates of variation of the different parameters were taken into account with respect to the reference standards (ERS/ATS 2005) $)^{4}$. The best test was selected taking into account the subject's degree of cooperation and the aspect of the flowvolume curve. Volumes, lung capacities and bronchial flows were examined (basic and post-bronchodilator spirometric parameters). The rates of variation of the various parameters in relation to the reference standards have been taken into account.

The parameters measured were the Maximum Expiratory Volume at the first second (FEV1), the Forced Vital Capacity (FVC), the Tiffeneau ratio (FEV1/FVC) and the maximum expiratory flows (FEF) including FEF75\%, FEF50\%, FEF25\% and FEF25$75 \%$. Obstructive syndrome was defined on the basis of a lower FEV1/FVC ratio (less than 80\%) and FEV1 < $80 \%$ of the predicted value. The diagnosis of obstructive ventilatory disorders was made according to the level of impairment in the airways:

- total obstruction: FEV1/FVC $<80 \%$ of the predicted value and $\mathrm{FEF}_{25-75 \%}<80 \%$ of the predicted value,

- proximal obstruction only: FEV1/FVC $<80 \%$ predicted value and $\mathrm{FEF}_{25-75 \%}$ normal,

- distal obstruction only: $\mathrm{FEF}_{25-75 \%<} 80 \%$ of the predicted value and FEV1/FVC normal.

The functional restriction was retained ahead of a decrease in CVF $<80 \%$ of the predicted value and a normal CVF1/CVF ratio ( $>80 \%)$.

\section{Statistical Analysis}

Data collection was based on pre-established survey forms and spirometric data forms using Excel 2013 software. The statistical analysis was done using Excel and Prism software. Qualitative variables were expressed in proportions and quantitative variables in terms of averages and standard deviations. The Student test was used to search for a link between the parameters. The limit of significance was set at $\mathrm{p}<0.05$.

\section{Results}

A total of forty (40) petrol pump attendants were recruited. The average age was $37.77 \pm 3.99$ years with a more represented age group of 40 to 50 years $(35 \%)$. 
The average BMI was $21.77 \pm 3.05 \mathrm{~kg} / \mathrm{m}^{2}$ (Table I). The seniority in the job was estimated at $9.4 \pm 7.05$ years. In addition, our subjects worked an average of $76 \pm 12$ hours per week with extremes ranging from 60 to 96 hours. Our study population was mainly composed of non-smokers $(55 \%)$ with a lower proportion of active smokers (20\%) having an average smoking consumption of 5.6 packs per year with extremes ranging from 2 to 13.5 packs per year.

All of our subjects wore safety shoes and uniforms based on the colour of their petrol station. However, none of them used gloves and only one gas station attendant reported that he wore a face mask during his shift. Four (4) employees had received a pre-employment medical examination, representing $10 \%$ of our study population. On the other hand, no employee received regular medical follow-up. Nevertheless, $52.5 \%$ of the petrol pump attendants recruited were unaware of the occupational risks related to fuel exposure when questioned.

The prevalence of respiratory function abnormalities was $85 \%$ in the study. Obstructive, restrictive or mixed ventilatory disorders were noted in our subjects. The most common ventilatory disorders (VD) were isolated obstructive types (45\%) which were mainly located in the distal bronchi ( $65 \%$ ). Besides, $27.5 \%$ of the subjects had mixed ventilatory disorders and a restrictive syndrome in $12.5 \%$ of the cases (Figure 1).

Depending on seniority in activity (duration of exposure), we noted at the beginning of exposure (group 1 to 10 years) a significantly higher prevalence of obstructive ventilatory disorders compared to restrictive syndrome $(\mathrm{p}=0.0001)$ and mixed syndrome $(\mathrm{p}=0.02)$. In addition, mixed ventilatory disorders increased significantly after 10 years of exposure $(26.9 \%$ of workers with 1 to 10 years of exposure compared to $28.6 \%$ of the group with more than 10 years of seniority $(\mathrm{p}=0.0001)$ (Figure 2).

Obstructive syndrome was significantly higher among ex-smokers than among smokers $(p=0.005)$. Furthermore, this syndrome is also significantly higher among active smokers compared to nonsmokers $(p=0.0001)$. Mixed ventilatory disorders were significantly higher among smokers compared to nonsmokers $(\mathrm{p}=0.0001)$ (Figure 3$)$.

The analysis of post-bronchodilation spirometry data made it possible to objectify $10 \%$ of work-related asthma cases in our study population (Figure 4). We noticed a negative correlation between the base FEV1 and seniority $(\mathrm{p}=0.0193$ and $\mathrm{r}=-0.36)$ (Figure 5).

\section{Discussion}

This study has identified the main work-related risks of the petrol pump attendant job in the informal economy in our country. Paradoxically, the decisive role of the petrol pump attendant in the operation of the petrol station exposes him to the health risks arising from the handling, especially of fuel distribution pistols, with the failure to comply with the safety measures often observed among these exposed groups. Workers at these petrol stations are in continuous contact with fuels and constantly inhale the particles emitted by the vehicles they refuel ${ }^{5}$. Moreover, the need for petrol pump attendants sometimes to sniff the tank cap to check the fuel type in order to avoid errors, results in overexposure to fuel fumes ${ }^{6}$. In our cross-sectional study, the results confirm a ventilatory function impairment of petrol pump attendants exposed to petrol / diesel fumes. Similar results have been observed in previous studies ${ }^{7,8}$. In our study, abnormalities in ventilation function are significant in $85 \%$ of the exposed subjects, which could be explained by the lack of use of personal protective measures (PPM) during work, poor air quality in petrol pumps, multiple tasks (refuelling, storage and workplace cleaning), and lack of knowledge about the harmful effects of fuels. Obstructive syndrome predominated in our exposed subjects. Pellegrino et $\mathrm{al}^{9}$ had found similar results with changes in FEV1 and FEV1 / FVC ratio more common than changes in FVC. The reduction in the FEV1 / FVC ratio may indicate a slight obstruction of the respiratory tract. Our results are consistent with what is found in the observations of Kesavachandrani et al. ${ }^{10}$ and Ayres et al. ${ }^{11}$ which showed that workers exposed to diesel and automatic exhaust systems had increased respiratory tract resistance. Studies involving particle distribution in the human lung have shown a major impact site in the terminal bronchioles ${ }^{12}$ where most chronic obstructive pulmonary disease begins ${ }^{13}$. It is clearly established that the loss of bronchiolar attachment due to the destruction of the extracellular matrix secondary to the deposition of toxic particles is the cause of the reduction in FEF25-75\% ${ }^{14,15}$.

The restrictive syndrome and the mixed deficit observed in our study seem predictable with regard to the substances handled and the working conditions. Indeed, repeated chemical aggression initially leads to obstruction, secondary alveolitis will lead to pulmonary 
fibrosis whose ventilatory expression is the restrictive syndrome ${ }^{16}$. Our study found an increase in respiratory failure among smokers. Many previous studies have shown the potentiating effect of tobacco on respiratory risk at work-related exposures ${ }^{17,18}$. Weisel et al.19 found that work-related inhalation exposure to benzene could be increased among employees who smoke.

The prevalence of asthma in our subjects is $10 \%$. Studies in healthy and asthmatic adult populations have shown a clear association between exposure to benzene and total volatile organic compounds (VOCs) on the one hand and, the occurrence of asthmatic respiratory manifestations (diagnosed asthma, clinical or functional symptoms suggestive of asthma $)^{20,21}$ on the other hand.

The increasing tendency of lung parenchyma involvement through an increase in mixed syndrome relative to seniority in exposure suggests a probable influence of exposure duration on respiratory function. Our results corroborate those of Solanki et $\mathrm{al}^{22}$ who observed that, as the duration of exposure increases, a progressive decrease in FEF25-75 and FEV1 / FVC, pointing to obstructive pathology and leading to a mixed type of respiratory deficit. In our work, negative correlations were found between job tenure and FEV1. These results could suggest an increase in bronchial muscle tone leading to a certain degree of bronchoconstriction in relation to an irritant effect related to VOC exposure ${ }^{23}$.

Table I: Anthropometric data

\begin{tabular}{|l|l|l|l|}
\hline Anthropometric data & Average & Min & Max \\
\hline Age (years) & $\begin{array}{l}37.77 \pm \\
3.99\end{array}$ & 21 & 59 \\
\hline Weight $(\mathrm{kg})$ & $\begin{array}{l}71.15 \pm \\
10.54\end{array}$ & 54 & 96 \\
\hline Height $(\mathrm{cm})$ & $\begin{array}{l}180.65 \pm \\
5.74\end{array}$ & 168 & 190 \\
\hline BMI $\left(\mathrm{kg} / \mathrm{m}^{2}\right)$ & $\begin{array}{l}21.77 \pm \\
\end{array}$ & 17 & 27 \\
\hline
\end{tabular}

BMI : Body Mass Index

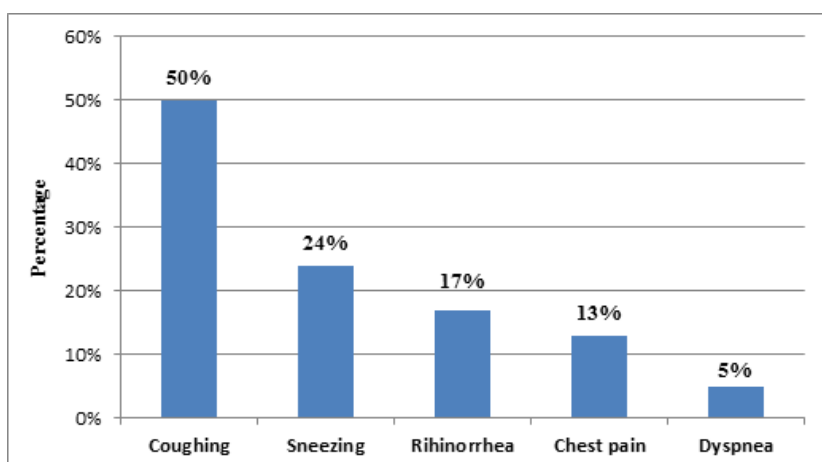

Figure 1 : Distribution of the population according to the different ventilatory disorders.

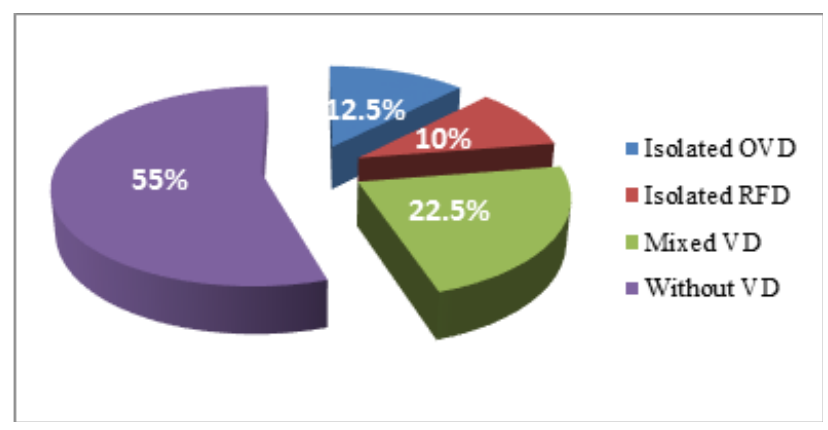

Figure 2: Distribution of ventilatory disorders by seniority (years).

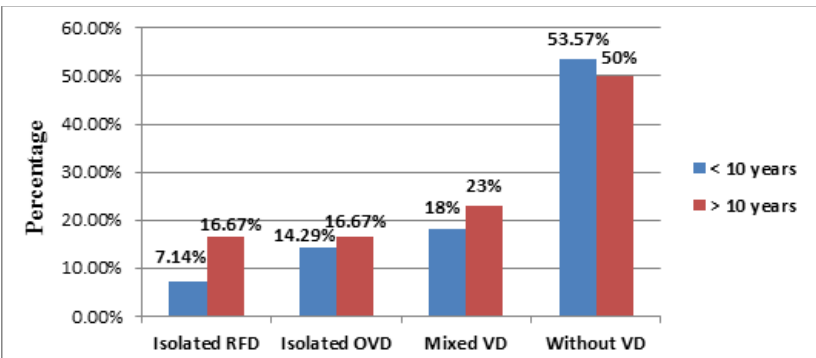

Figure 3: Distribution of ventilatory disorders by smoking status

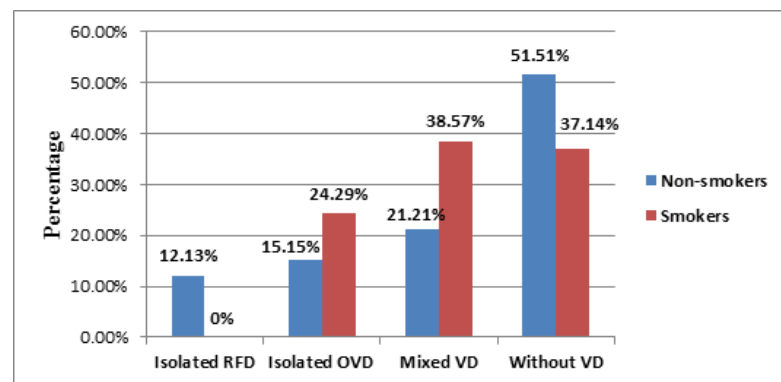

Figure 4: Prevalence of asthma in our population.

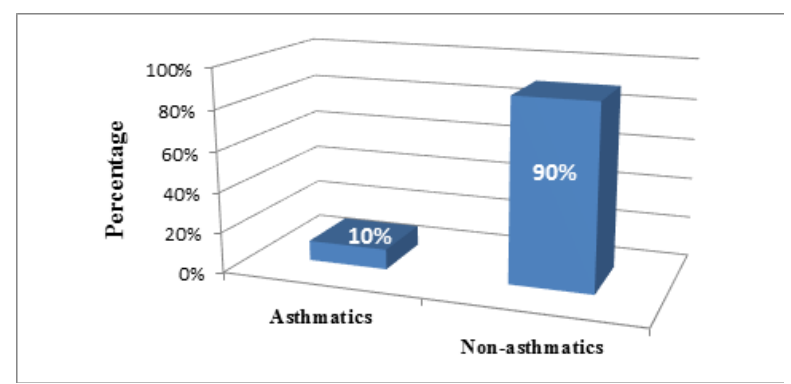

Figure 5: Correlation between FEV1 and seniority. 


\section{Conclusion}

The prevalence of ventilatory disorders is high in the petrol pump worker environment. Small airways are probably the most critical site of lung damage. Smoking and seniority in the job increase the risks associated with fuel exposure. Frequent health check-ups and regular follow-up of ventilation function would be beneficial. The proper use of safety measures such as protective masks, gloves could be adopted to reduce the health risks associated with chronic exposure to fuels. Enhanced individual and collective protection measures must be implemented to reduce the health risks associated with fuel exposure.

Ethical Clearance: Ethics committee of the University of Thies

\section{Source of Funding - Self}

\section{Conflict of Interest: Nil}

\section{References}

1. Kaung S, Liang W. Clinical analysis of 43 cases of chronic benzene poisoning, Chemico-Biological Interactions $2005: 153-154$

2. Vinegar A, Carson A, Pepelko WE. Pulmonary function changes in Chinese hamsters exposed six months to diesel exhaust. Env Internal 1981; 5: 369-71.

3. Mauderly JL. Life-span of rodents inhaling diesel exhaust: results through 30 months. Inhal Toxicol Res Inst Ann Rep 1983 : 305-16.

4. Brusasco V, Crapo R, Viegi G. Recommandations communes de l'ATS et de l'ERS sur les explorations fonctionnelles respiratoires. Revue des Maladies Respiratoires 2007 ; 24(3) : 11-14.

5. Wiwanitkit V, Suwansaksri J, Nasuan P. Research note: Urine trans, trans-muconic acid as a biomarker for benzene exposure in gas station attendants in Bangkok, Thailand. Ann. Clin. Lab. Sci 2001 ; 31 : 399-401.

6. Ferreira MC, Freire ON. Carga de Trabalho e Rotatividade naFunção de Frentista. RAC 2001; 5 :175-200.

7. Singhal M, Khaliq F, Singhal S, Tandon OP. Pulmonary function in petrol pump workers: A preliminary study. Indian J Physiol Pharmacol 2007;51:244-5.
8. Hulke SM, Patil PM, Thakare AE, Vaidya YP. Lung function test in Petrol Pump workers. National J PhysiolPharmaPharmacol2012;2:71-5.

9. Pelligrino R, Viegi G, Brusasco V, Crapo RO, Burgos F, Casaburi R et al. Interpretative strategies for lung function test. Eur. Respir. J 2005 ; 26 : 948-968.

10. Kesavachandrani C, Rastogi SK, Anand M, et al. Lung function abnormalities among petrol-pump workers of Lucknow, North India. Current Science 2006; 90: 1177-1178.

11. Ayres SM, Evans R, Licht D, Griesbach J. Health effects of exposure to high concentrations of automotive emissions. Arch Environ Health 1973; 27: 168-78.

12. Pinkerton KE, Green FH, Saiki C, Vallyathan V, Plopper CG, Gopal V, et al. Distribution of particulate matter and tissue remodeling in the human lung. Environ Health Perspect 2000; 108: 1063-9.

13. Roux M, Duracher C. Physiologie bronchique. Physiologie humaine appliquée $2^{\text {ème }}$ édition. Editions Arnette 2017: 900 p.

14. Udwalia F.E, Shetye V.M. The Maximum expiratory flow volume curve in normal subjects in India. Chest Journal 1986; 89(6): 852-56.

15. Moorman WJ, Clark JC, Pepelko WE, Mattox J. Pulmonary function responses in cats following long-term exposure to diesel exhaust. J Appl Toxicol 1985; 5(5): 301-5.

16. Foray JP. Rappel de la situation réglementaire en matière de pollution : quelles implications de la nouvelle directive COV-Solvants sur le secteur de la peinture industrielle ? In : Peintures industrielle et nouvelles technologies. La Documentation Professionnelle, Paris Euroforum 1998: 20p.

17. Laraqui HC. H, Laraqui HO, Rahhali AE et al. Risques respiratoires chez les ouvriers des menuiseries ébénistes artisanales. Rev Mal Respir 2001; 18:615-622.

18. Wieslander G, Norback D, Edling C. Occupational exposure to water-based paint and symptoms from the skin and eyes. Occup Environ Med 1994; 51:181-6.

19. Weisel CP. Benzene exposure: An overview of monitoring methods and their findings. Chem. Biol. Interact 2010; 184: 58-66. 
20. Rumchev K, Spickett J, Bulsara M et al. Association of domestic exposure to volatil organic. Compounds with asthme in young children. Thorax 2004; 59: 746-751

21. Mitha N, Lévy J, Annesi-Maesano I, Lafortune J, Magnier AM, Ibanez G. Pollution de l'air intérieur et asthme chez l'adulte. Revue des Maladies Respiratoires 2013; 30: 374 - 413
22. Solanki RB, Bhise AR, Dangi BM. A study on spirometry in petrol pump workers of Ahmedabad, India. Lung India 2015; 32 (4) : 347-352.

23. Noertjojo HK, Dimich-Ward H, Peelen $\mathrm{S}$ et al. Western red cedar dust exposure and lung function: a dose-response relationship. Am J Respir Crist Care Med 1996; 154 : 968-73 